\title{
A INFRAESTRUTURA COMO ELEMENTO DO DIREITO HUMANO AO DESENVOLVIMENTO NO MARCO DA INTEGRAÇÃO REGIONAL SUL- AMERICANA
}

\author{
Joaner Campello de Oliveira Junior ${ }^{1}$ \\ Roberto Correia da Silva Gomes Caldas ${ }^{2}$
}

\begin{abstract}
RESUMO: O marco fundacional da IIRSA foi a Primeira Reunião de Presidentes Sulamericanos ocorrida em Brasília, no ano 2000. Dentre os vários temas abordados, ganhou relevância a construção de uma agenda comum para impulsionar o processo de integração de infraestrutura de transportes, energia e comunicações, buscando estabelecer projetos capazes de melhorar, dentre outros fatores, a qualidade de vida das populações locais e promover o desenvolvimento regional. Considerando o marco jurídico internacional que reconhece o direito ao desenvolvimento como direito humano, o objetivo do presente trabalho é analisar a infraestrutura como elemento integrante de tal direito no âmbito da integração regional sulamericana.
\end{abstract}

Palavras-Chave: Infraestrutura; Integração Regional; Direitos Humanos; Direito Internacional; Desenvolvimento.

\section{THE INFRASTRUCTURE AS AN ELEMENT OF HUMAN RIGHT TO DEVELOPMENT IN THE FRAMEWORK OF REGIONAL SOUTH AMERICAN INTEGRATION}

\begin{abstract}
The founding milestone of IIRSA was the First Meeting of South American Presidents, held in Brasilia, in 2000. Among the various debated topics, it was important the construction of a common agenda to boost the process of integration of transport infrastructure, energy and communications, looking for projects capable of improving, among other factors, the quality of life of local populations and regional development. Considering the international legal framework that prescribes the right to development, it is important to analyze infrastructure as an integrating element of the right to development within the framework of regional integration of South American infrastructure.
\end{abstract}

Keywords: Infrastructure; Regional Integration-Human Rights-Development-International law

\footnotetext{
${ }^{1}$ Advogado. Pós-Graduado em Direito Público e Tributário pela AVM Educacional. Mestre em Direito das Relações Internacionais e da Integração Latino Americana pela Universidad de la Empresa - Uruguai. E-mail: joanercampello@hotmail.com.

${ }^{2}$ Doutor em Direito do Estado pela PUC-SP. Professor dos Cursos de Mestrado e bacharelado em Direito na UNINOVE. Diretor do Instituto dos Advogados de São Paulo (2013-2015). Advogado. E-mail: robertocsgcaldas@uol.com.br
} 


\section{INTRODUÇÃO}

A Iniciativa para Integração da Infraestrutura Sul-americana (IIRSA), conforme será analisado no presente artigo, nasceu da primeira reunião de Presidentes sul-americanos ocorrida em Brasília, no ano 2000. Na ocasião, dentre os diversos temas importantes para o espaço sub-regional, enfatizou-se a necessidade de fortalecer a integração regional de infraestrutura de transportes, energia e comunicações.

Dentre os inúmeros objetivos estabelecidos no Comunicado de Brasília, e no consequente Plano de Ação naquela ocasião adotado, observam-se, dentre outras medidas, a preocupação de valorizar a dimensão ambiental e social dos projetos, assim como a busca por projetos de integração regional que melhorem a qualidade de vida das populações locais.

Durante o desenvolvimento dos trabalhos no âmbito da IIRSA, considerada como um fórum de diálogo dos 12 (doze) Estados sul-americanos, esta foi incorporada pelo COSIPLAN (Conselho Sul-americano do Planejamento), órgão da UNASUL (União das Nações Sul-americanas), sendo que esta última, no seu tratado constitutivo, declara como seu objetivo principal construir um espaço de integração e união no âmbito cultural, social, econômico e político, dando prioridade, dentre outras questões, à infraestrutura, com vistas a eliminar a desigualdade socioeconômica, alcançar a inclusão social e incrementar a participação cidadã.

Diante deste contexto, e considerando que o direito ao desenvolvimento está positivado na ordem jurídica internacional, ao apontar a Constituição Federal de 1988 delineamentos relativos ao tema (do desenvolvimento) e reconhecer a infraestrutura como elemento catalizador para sua persecução, percebe-se claramente sua atualidade e relevância.

Deve-se examinar em que medida a infraestrutura pode ser interpretada como elemento integrante do direito ao desenvolvimento no âmbito da integração regional sulamericana, vez que a IIRSA conta com uma vultosa carteira de projetos cujos resultados, ainda que pouco expressivos, consoante será observado, vinculam os Estados participantes no que tange ao seu planejamento e execução; tais projetos, vale ressaltar, afetam sobremaneira as populações envolvidas e, consequentemente, representam um desafio para a concretização do direito ao desenvolvimento.

Assim, o trabalho analisa, ainda que brevemente, a formação da IIRSA e seus desdobramentos concernentes à questão da infraestrutura, bem como estabelece os pressupostos para o reconhecimento do direito ao desenvolvimento como direito humano, na 


\section{A INFRAESTRUTURA COMO ELEMENTO DO DIREITO HUMANO AO DESENVOLVIMENTO NO \\ MARCO DA INTEGRAÇÃO REGIONAL SUL-AMERICANA}

ordem internacional e nacional, e sua conseguinte aplicação no âmbito da integração regional sul-americana.

Para a consecução deste objetivo, utilizou-se o método indutivo, de sorte a ter-se, a partir dos elementos em que caracterizada a infraestrutura dos projetos da IIRSA, sua verificação enquanto componente do direito ao desenvolvimento o qual, a seu turno, passa a inserir-se dentre o rol dos direitos fundamentais. Tal pesquisa dá-se mediante a técnica de abordagem bibliográfica, cujas fontes extraídas incorporam a literatura especializada impressa e digital sobre a temática proposta.

\section{A INICIATIVA PARA INTEGRAÇÃO DE INFRAESTRUTURA REGIONAL SUL- AMERICANA (IIRSA): BREVES CONSIDERAÇÕES}

O Primeiro Encontro dos Presidentes sul-americanos, realizado em Brasília no ano 2000, ocorreu no contexto das comemorações dos 500 (quinhentos) anos de descobrimento do Brasil. Na ocasião, os mandatários dos 12 (doze) países sul-americanos trataram de diversos temas relevantes para o fortalecimento da região, como combate às drogas ilícitas, promoção dos valores democráticos, incremento do comércio inter-regional, entre outros; também concordaram os referidos mandatários em construir uma agenda comum para impulsionar o processo de integração da infraestrutura regional de transportes, energia e comunicações.

O Comunicado de Brasília (IIRSA, 2000a), documento final firmado pelos participantes, contemplou um capítulo voltado para a integração de infraestrutura com a assunção de importantes objetivos para o espaço sub-regional ao fixar que

\footnotetext{
i) As fronteiras sul-americanas devem se tornar um espaço de união para a circulação de bens e pessoas, conformando-se num espaço de cooperação; ii) Integração e desenvolvimento de infraestrutura são duas linhas de ação complementares, assim como consideraram prioritária a identificação de obras de interesses bilateral e sub-regional; iii) Os mandatários estabeleceram um plano de ação com um horizonte de dez anos para a ampliação e a modernização de infraestrutura física da América do Sul; iv) Os Presidentes enfatizaram a importância motriz da energia, dos transportes e das redes de comunicações para a integração dos países da América do Sul; iv) No campo dos transportes concordaram os países em dar prioridade no desenvolvimento de redes multimodais para melhor articular a utilização as vias terrestres, fluviais, marítimas e aéreas, assim como facilitar o trânsito transfronteiriço de pessoas, veículos e cargas.
}

No Comunicado de Brasília, também se previu a convocação de uma reunião em Montevidéu, em dezembro do mesmo ano, com o escopo de consolidar uma visão integrada sobre as linhas de ação para a ampliação e modernização da infraestrutura na América do Sul. Esta reunião contou com a presença dos Ministros de Transportes, Energia e 
Telecomunicações dos Estados signatários, e estabeleceu o Plano de Ação para a Integração da Infraestrutura Regional da América do Sul (IIRSA, 2000b), onde foram previstas as seguintes ações básicas destinadas especificamente ao tema da infraestrutura

\begin{abstract}
Desenhar uma visão mais integral da infraestrutura que abarque todos os seus componentes e sinergias; Enquadrar os projetos dentro de uma planificação estratégica, organizada a partir da identificação dos eixos de integração e desenvolvimento regionais do continente sul-americano; Reformar e atualizar os sistemas regulatórios e instituições que normatizem o uso das infraestruturas nacionais; Fortalecer as capacidades dos Estados na formulação de políticas, planos e marcos regulatórios; Harmonizar as políticas, os planos e marcos regulatórios e institucionais entre os Estados; Valorizar a dimensão ambiental e social dos projetos; Procurar que os projetos de integração regional melhorem a qualidade de vida das populações locais; Incorporar mecanismos de participação e consenso; Desenvolver novos mecanismos regionais para a programação, execução e gestão de projetos de integração física; Otimizar o uso de fontes de financiamento desenvolvendo estratégias comuns ${ }^{3}$.
\end{abstract}

É importante ressaltar que, segundo López (2012), a visão da infraestrutura física como elemento chave para a integração sul-americana está baseada na noção de que o desenvolvimento sinérgico de transporte, energia e telecomunicações pode gerar um impulso decisivo para a superação de barreiras geográficas, a aproximação de mercados e a promoção de novas oportunidades econômicas na região, melhorando, assim, a qualidade de vida da população.

Assim, com o intuito de atingir as finalidades estabelecidas no Plano de Ação conforme anteriormente descritas, foram ratificados em reunião do Comitê de Direção Executiva (CDE), órgão da IIRSA, os princípios norteadores que devem ser observados pelos Estados, a saber: i) o regionalismo aberto; ii) os eixos de integração e desenvolvimento (EID); iii) a sustentabilidade econômica, social, ambiental e político institucional; iv) o aumento do valor agregado da produção; v) a utilização das tecnologias da informação; vi) a consecução da convergência normativa; e, finalmente, vii) a coordenação dos setores público e privado (Mata Diz e Souza, 2015).

Para desenvolver a Carteira de Projetos, a IIRSA estabeleceu a criação e a aplicação de um planejamento territorial. Assim, os trabalhos de planejamento e ordenamento territorial geraram resultados pelo agrupamento de projetos com características e/ou finalidades comuns, que permitiram a identificação de grupos de projetos dentro de cada EID, priorizando-se

\footnotetext{
${ }^{3}$ Para consulta das diretrizes para a integração física da América do Sul, ver: Plano de Ação da IIRSA. Disponível em: http://www.iirsa.org/admin_iirsa_web/Uploads/Documents/plan\%20de\%20accion\%20de\% 201a\%20iniciativa\%20iirsa.pdf. Acesso em: 15 de novembro de 2014.
} 
aqueles com maior impacto em relação ao desenvolvimento, e cuja consecução estaria caracterizada pela facilidade de realização.

Vale ressaltar que um grupo de projetos, nesse contexto, é um conjunto interdependente de ações em um determinado espaço geoeconômico e que apresenta efeitos sinérgicos sobre o desenvolvimento sustentável.

Em um segundo momento, a planificação territorial foi marcada por um aprofundamento e incremento da qualidade do planejamento, principalmente pela criação de novas ferramentas de análise e metodologias de planejamento representadas, entre outros: pelo sistema de informação georreferenciada - Programa GeoSur; pela metodologia de integração produtiva e logística (IPrLg); pelo sistema de informação para gestão estratégica (SIGE); pela avaliação de projetos transnacionais de infraestrutura e Avaliação social e ambiental com enfoque estratégico (EASE) (Mata Diz e Souza, 2015).

Paralelamente, os projetos foram agrupados de acordo com os Eixos de Integração e Desenvolvimento (EID), nos quais o território multinacional é delimitado ou classificado como Processos Setoriais de Integração sem limites territoriais, visando, principalmente, superar obstáculos de natureza normativa, englobando os 12 (doze) Estados-membros.

Desse modo, para cada EID foram identificadas as necessidades de infraestrutura física a fim de articular o território com o resto da região e planejar os investimentos de modo a melhorar a qualidade de vida de seus habitantes.

Atualmente, a IIRSA possui uma carteira de projetos com 562 (quinhentos e sessenta e dois) projetos de infraestrutura distribuídos em 10 (dez) Eixos de Integração e Desenvolvimento. Para dinamizar o processo, foi definida uma agenda de implementação consensuada de 31 (trinta e um) projetos prioritários, assim definidos pelo seu alto impacto na integração física da América do Sul.

Em 2011, a IIRSA foi incorporada à UNASUL como parte do fórum técnico do Conselho Sul-Americano de Infraestrutura e Planejamento (COSIPLAN) (Dabéne, 2014). Assim, o COSIPLAN, por sua vez, tornou-se a instância de discussão política e estratégica destinada a promover a articulação de ações que deverão viabilizar a integração de infraestrutura, consoante disposto nos instrumentos constitutivos anteriormente descritos (Comunicado de Brasília e Plano de ação). Sua criação deu-se, portanto, em virtude da necessidade de se criar uma estrutura técnico-formal que viesse a gerenciar as prioridades e estratégias da Iniciativa. Conforme Padula (2013, p. 588) 
Na III Reunião Ordinária de Chefes de Estado e de Governo da Unasul, em agosto de 2009, foi decidida a criação do Conselho de Infraestrutura e Planejamento (Cosiplan) - mais um resultado da liderança do governo brasileiro no processo de institucionalização da integração regional. A criação do Cosiplan almeja alcançar maior controle e respaldo político por parte dos governos sobre o tema da infraestrutura, e a partir disso avançar para uma visão política e estratégica e uma maior capacidade de alavancar recursos e gerar diferentes formas de financiamento, agregando diferentes agentes (além dos que participam do CCT) e indo além de fatores meramente técnicos para a avaliação, viabilização, execução e financiamento de projetos.

É importante realçar que por ocasião da Primeira Reunião da UNASUL, no dia 23 de maio de 2008 (ocorrida em Brasília), os mandatários dos países sul-americanos aprovaram o Tratado Constitutivo da UNASUL, que entrou em vigor de março de 2011, sendo promulgado pelo Decreto ${ }^{\circ} 7.667$ de 11 de janeiro de 2012. Vale mencionar que o Tratado da UNASUL nasceu sob inspiração das Declarações de Brasília, Cusco e Cochabamba, conforme informa Nery (2016), e tem como objetivo principal a construção de uma identidade e cidadania sulamericanas em um espaço integração nas esferas política, econômica, social, ambiental e infraestrutura.

Diante do exposto, a IIRSA concretiza-se como um fórum de diálogo regional que apresenta como principal objetivo a consolidação de uma estrutura física que possibilite uma rede de conexão viária, aeroportuária e marítima entre os países sul-americanos, proporcionando maior cooperação na circulação de mercadorias, na gestão da informação e na geração de energia ${ }^{4}$.

Ao transformar-se em instância do COSIPLAN, adota como prioridade uma agenda voltada para a infraestrutura, com vistas a eliminar a desigualdade socioeconômica, alcançar a inclusão social e a participação cidadã, reiterando o escopo de desenvolvimento de uma infraestrutura para a interconexão da região e dos povos sul-americanos, conforme critérios pautados no desenvolvimento social, proteção ambiental e crescimento econômico.

Passados 18 (dezoito) anos de conformação da IIRSA, seus resultados ainda são pouco expressivos. Afinal, dada a importância dos projetos de infraestrutura para colimar os objetivos da integração regional sul-americana, apenas 160 (centro e sessenta) projetos foram concluídos, o que representa 28,47\% (vinte e oito vírgula quarenta e sete por cento) da carteira total de projetos, ao passo que 237 (duzentos de trinta e sete) projetos se encontram

\footnotetext{
${ }^{4}$ No mesmo sentido Carvalho e Rosevics (2013, p.234) para quem "A IIRSA tem, entre seus princípios ordenadores, o objetivo de estabelecer uma integração pautada em um regionalismo aberto, sustentável de maneira econômica, social, ambiental e político-institucional, que possibilite o aumento do valor agregado da produção dos países da região".
} 
nas etapas de perfil e pré-execução, enquanto 165 (cento e sessenta e cinco) projetos estão em execução ${ }^{5}$.

A baixa performance de execução de projetos apresentada pela IIRSA é constatada por López (2012) ao referir-se ao relatório de avaliação e supervisão formulado pelo BID (Banco Interamericano de Desenvolvimento), onde se indica que a IIRSA obteve índice regular nos indicadores mais importantes de integração adotados pelo próprio Banco, tais como, o aumento do comércio inter-regional, melhores indicadores de qualidade da infraestrutura, aumento nas parcerias público-privadas, a adoção de ferramentas de planejamento pelos Estados-membros, sublinhando o abandono de qualquer visão estratégica significativa para a integração sul-americana.

Destarte, Caldas e Oliveira Junior (2016) ao analisarem a integração regional no âmbito da IIRSA e a implementação de políticas públicas no caso brasileiro, observam que a realização e o desenvolvimento da carteira de projetos dependem da execução eficiente dos projetos pelos países integrantes.

No caso brasileiro, os supracitados autores (Caldas; Oliveira Junior, 2016) afirmam que as políticas públicas, vocacionadas à integração regional sul-americana por meio da criação de uma infraestrutura física no Brasil, estão compreendidas no planejamento estatal estratégico expressado pelos PPA's - Planos Plurianuais, em seus projetos, programas e planos, complementados, ainda, pelas respectivas LDO's - Leis de Diretrizes Orçamentárias e LOA's - Leis Orçamentárias Anuais. E ainda em Programas como os de Aceleração do Crescimento, de Investimentos em Logística, de Dragagem Portuária e Hidroviária, dentre outros (Caldas; Oliveira Junior, 2016).

Não obstante, ressaltam que o planejamento estratégico regional revela um déficit democrático participativo e, de consequência, de legitimidade e efetividade das políticas regionais que a IIRSA visa concretizar, pois percebe-se uma carência de vias diretas de diálogo institucionalizado que pressuponha a participação popular e controle social direto, ou por intermédio da sociedade civil organizada representativa de diversos setores (Caldas; Oliveira Junior, 2016).

Esta análise se coaduna com as palavras de Gonçalves e Oliveira (2011, p. 19), já que "é preciso conscientizar a população e a classe política da necessidade da integração". Todavia, as divergências entre os governos dos Estados e suas consequentes mudanças de

\footnotetext{
${ }^{5}$ Disponível em www.iirsa.org.br/proyectos. Acesso em 01 de setembro de 2018
} 
orientação política no âmbito sul-americano, em si, contribuem para o arrefecimento da integração regional.

Neste sentido, Nunes e Rodrigues (2017) asseveram que a política externa brasileira, após a gestão Temer, contribuiu, no âmbito regional, com a substituição da UNASUL e da IIRSA por reuniões bilaterais e pela busca da exclusão da Venezuela do MERCOSUL, o que, em certa medida, explica a crise hodiernamente vivida pela própria UNASUL.

\title{
2. O DESENVOLVIMENTO COMO DIREITO HUMANO
}

O termo desenvolvimento, em sentido denotativo, significa ação de desenvolver-se, crescimento, progresso, adiantamento; já o termo crescimento, possui caráter plurissignificativo, podendo representar tanto o sentido de crescimento econômico como social e político de um país, comunidade e/ou região. Conforme Martinelli (2012, p.406), “o desenvolvimento pode ser social, humano, econômico, científico, ambiental, etc. Enfim, todas as áreas do desenvolvimento humano admitem o desenvolvimento".

Embora, por vezes, o desenvolvimento seja acompanhado da ideia de crescimento, dela difere à medida em que o desenvolvimento deve representar um processo dinâmico e harmonioso, estrutural e sustentável, acarretando mudanças sociais acompanhadas de transformações tecnológicas. Conforme ressaltam Caldas e Mata Diz

\begin{abstract}
A distinção que deve fazer-se entre o direito do desenvolvimento e o direito ao desenvolvimento, implica entender-se pelo primeiro, o conjunto de ferramentas jurídicas e sociais (e também das instituições) que dá ênfase ao desenvolvimento dos Estados - ditos subdesenvolvidos - por intermédio da cooperação internacional, visando à melhora qualitativa das condições de vida dos seres humanos em seu território, e, pelo segundo, o direito fundamental a esta melhora, enquanto categoria do direito de solidariedade, ou seja, o direito fundamental alicerçado nas relações jurídicas que reconhecem aos indivíduos, povos, coletividades regionais internas, grupos vulneráveis e minorias a faculdade de obterem da comunidade internacional, e dos seus próprios Estados, o objeto dessa relação (desenvolvimento visto como a promoção do bem-comum). (2016, p. 159-160)
\end{abstract}

No âmbito jurídico internacional, o direito ao desenvolvimento ${ }^{6}$ exsurge inicialmente a partir da Declaração Universal dos Direitos do Homem das Nações Unidas, em 1948. Neste aspecto, tal direito encontra-se prescrito no artigo $\mathrm{XXII}^{7}$ da referida declaração.

\footnotetext{
${ }^{6}$ Sem a pretensão de esgotar o tema, mas apresentar linhas gerais, se traz à colação a observação de Martinelli (2012) que afirma haver uma diferenciação entre o Direito do Desenvolvimento e o Direito ao Desenvolvimento. Este primeiro se relaciona com o Direito Internacional Econômico, já o segundo caracteriza um direito humano e fundamental.

${ }^{7}$ Todo homem, como membro da sociedade, tem direito à segurança social e à realização, pelo esforço nacional, pela cooperação internacional e de acordo com a organização e recursos de cada Estado, dos direitos
} 
Além da referência supra descrita, a terminologia do desenvolvimento pode ser encontrada em outras disposições normativas, como é o caso dos arts. 55 e 56, da Carta de São Francisco, marco jurídico da Carta das Nações Unidas. ${ }^{8}$

De modo sucinto, pode-se realizar uma cronologia que se inicia com a Resolução da Assembleia Geral das Nações Unidas n. 626 (VII), de 1952, e desemboca com a Declaração sobre Direito ao Desenvolvimento, adotada no marco da Resolução n. 41/128 da Assembleia Geral das Nações Unidas, em 4 de Dezembro de 1986, que conceitua no seu art. $1^{\circ}$ o direito ao desenvolvimento como

Um direito humano inalienável, em virtude do qual toda pessoa e todos os povos estão habilitados a participar do desenvolvimento econômico, social, cultural e político, a ele contribuir e dele desfrutar, no qual todos os direitos humanos e liberdades fundamentais possam ser plenamente realizados.

Contudo, entre a Resolução de 1952 e a Declaração de 1986, foram adotadas algumas resoluções no intento de concretizar os postulados do desenvolvimento a partir da vinculação deste direito, não só ao próprio direito internacional - como parte intrínseca dos direitos humanos e do direito de autodeterminação -, mas também à atuação dos Estados no plano interno, como ente garantidor dos direitos fundamentais.

A partir deste marco, o tema do direito ao desenvolvimento passa a ser recorrente na agenda da ONU, reforçada pela criação da Comissão de Direitos Humanos da ONU que reconheceu tal direito por meio da Resolução $\mathrm{n}^{\circ}$ 04, artigo XXXIII, de 21 de fevereiro de 1977, assim como, em 02 de março de 1979, por intermédio da Resolução $\mathrm{n}^{\circ}$ 05, artigo $\mathrm{XXXV}$, reiterando-se, desta forma, a existência deste direito, afirmando constituir um direito humano fundamental e, outrossim, que a igualdade de oportunidade é uma prerrogativa tanto dos indivíduos quanto das nações.

Todavia, o conteúdo dado a esse direito encontrava-se ainda em construção, o que contribuiu para que a Comissão de Direitos Humanos da ONU não alcançasse o consenso

econômicos, sociais e culturais indispensáveis a sua dignidade e ao livre desenvolvimento de sua personalidade. Ver em: Declaração Universal dos Direitos Humanos. Disponível em: <http://www.onu.org.br/img/2014/09/DUDH.pdf>. Acesso em: 28 de agosto de 2018.

${ }^{8}$ Art. 55 - Com o fim de criar condições de estabilidade e bem-estar necessárias às relações pacíficas e amistosas entre as Nações, baseadas no respeito ao princípio da igualdade de direitos e da auto determinação dos povos, as Nações Unidas favorecerão: a) níveis mais altos de vida, de trabalho efetivo, e condições de progresso e desenvolvimento econômico e social; b) a solução de problemas econômicos, sociais, sanitários e conexos; a cooperação internacional, de caráter cultural e educacional; c) $\mathrm{O}$ respeito universal e efetivo dos direitos humanos e das liberdades fundamentais para todos, sem distinção de raça, sexo, língua ou religião; Art. 56 Para a realização dos propósitos enumerados no art. 55, todos os membros da Organização se comprometem a agir em cooperação com esta, em conjunto ou separadamente. Ver em: Carta das Nações Unidas e Estatuto da Corte Internacional de Justiça. Disponível em: 〈https://nacoesunidas.org/docs/carta_da_onu.pdf >. Acesso em: 28 de agosto de 2018 . 
necessário entre os Estados para a aprovação das referidas Resoluções, especialmente em virtude da abstenção de alguns membros.

Assim, diante da necessidade de uma institucionalização abrangente e sistemática desse direito no marco das Nações Unidas, os membros da Comissão decidiram criar um grupo de trabalho para elaborar uma declaração sobre o direito ao desenvolvimento, resultando na Resolução 36 (XXXVII), de 11 de março de 1981 (Peixinho e Ferraro, 2013).

Esse esforço inicial, permeado por constantes divergências, restou por derivar na confecção da Resolução 41/128, da Assembleia Geral das Nações Unidas, que dá surgimento à Declaração sobre o Direito ao Desenvolvimento de 1986, confirmando que o direito ao desenvolvimento é um direito humano inalienável e que a igualdade de oportunidade para o desenvolvimento é uma prerrogativa tanto das nações quanto dos indivíduos.

É importante ressaltar que, segundo o seu art. $3^{\circ}, \S 1^{\circ}$, os Estados têm responsabilidade pela criação de condições nacionais e internacionais favoráveis à realização do direito ao desenvolvimento, dispositivo reforçado pelo prescrito no $\S 3^{\circ}$ do citado artigo, onde se destaca que os Estados têm o dever de cooperar para assegurar o desenvolvimento e eliminar os obstáculos ao desenvolvimento 9 .

O Relatório Brundtland, ao seu turno, exsurge na subsequência dos acontecimentos constituindo-se num documento (intitulado Nosso Futuro Comum e, publicado em 1987), confeccionado pela Comissão Mundial sobre Meio Ambiente e Desenvolvimento, que influenciou, inclusive, a redação do art. 225, da nossa Constituição Federal de 1988, ao, pela primeira vez, versar o conceito de sustentabilidade do desenvolvimento.

Em 1992, na Declaração do Rio sobre o Meio Ambiente e Desenvolvimento, o tema do desenvolvimento já passa a ser abordado sob a ótica do desenvolvimento sustentável, estabelecendo no seu Princípio 3 que "o direito ao desenvolvimento deve ser exercido de

\footnotetext{
${ }^{9}$ Artigo $1^{\circ}, \S 1^{\circ}$. O direito ao desenvolvimento é um direito humano inalienável, em virtude do qual toda pessoa e todos os povos estão habilitados a participar do desenvolvimento econômico, social, cultural e político, para ele contribuir e dele desfrutar, no qual todos os direitos humanos e liberdades fundamentais possam ser plenamente realizados. $\S 2^{\circ}$. O direito humano ao desenvolvimento também implica a plena realização do direito dos povos à autodeterminação que inclui, sujeito às disposições relevantes de ambos os Pactos Internacionais sobre Direitos Humanos, o exercício de seu direito inalienável à soberania plena sobre todas as suas riquezas e recursos naturais; Artigo $3^{\circ}$. §1. Os Estados têm a responsabilidade primária pela criação das condições nacionais e internacionais favoráveis à realização do direito ao desenvolvimento. §3. Os Estados têm o dever de cooperar uns com os outros para assegurar o desenvolvimento e eliminar os obstáculos ao desenvolvimento. Os Estados deveriam realizar seus direitos e cumprir suas obrigações, de modo tal a promover uma nova ordem econômica internacional, baseada na igualdade soberana, interdependência, interesse mútuo e cooperação entre todos os Estados, assim como a encorajar a observância e a realização dos direitos humanos. Ver em: Declaração sobre o Direito ao desenvolvimento de 1986. Disponível em: <http://www.direitoshumanos.usp.br/index.php/Direito-aoDesenvolvimento/declaracao-sobre-o-direito-ao-desenvolvimento.html>. Acesso em: 28 de agosto de 2018.
} 


\section{A INFRAESTRUTURA COMO ELEMENTO DO DIREITO HUMANO AO DESENVOLVIMENTO NO \\ MARCO DA INTEGRAÇÃO REGIONAL SUL-AMERICANA}

modo a permitir que sejam atendidas equitativamente as necessidades de desenvolvimento e de meio ambiente das gerações presentes e futuras", bem como noutro princípio, que "a proteção ambiental deve se constituir uma parte integrante do processo de desenvolvimento" $(\text { Princípio } 4)^{10}$.

No âmbito da Declaração de Viena, em 1993, também foi regulamentado o direito humano ao desenvolvimento, ao estabelecer em seu art. 10 que "A conferência Mundial dos Direitos Humanos reafirma o direito ao desenvolvimento conforme estabelecido na Declaração sobre o Direito ao Desenvolvimento, como um direito universal e inalienável e parte integrante dos direitos humanos fundamentais"11.

Kinoshita e Fernandes (2008) assinalam que, numa perspectiva histórica, a expressão ““direito ao desenvolvimento' propriamente dita foi utilizada pela primeira vez em 1971 na conferência inaugural do Instituto de Direitos Humanos de Strasbourg por Etiene Keba M' Baye”. E ainda, conforme ressalta Moisés (1998, p. 50) “...a Assembleia Geral, assim como a Comissão de Direitos Humanos, vem enfatizando que o direito ao desenvolvimento constitui um direito humano e a igualdade de oportunidades para o desenvolvimento, uma prerrogativa das nações, assim como dos indivíduos".

Doutrinariamente, Segunpta (2013) descreve o direito humano como um direito inalienável exercido em um processo dialógico, por meio do qual os direitos e as liberdades fundamentais podem ser realizadas mediante a possibilidade de participação de cada pessoa, e dos povos, em processos, dentro dos quais se discute inclusive desenvolvimento.

Segundo Bedin (2003), o direito ao desenvolvimento se insere entre os direitos de quarta geração, junto à autodeterminação dos povos, o direito à paz, o direito aos patrimônios comuns da humanidade e o direto ao meio ambiente sadio. Evidencia-se que tal geração de direitos pode ser denominada como de direitos de solidariedade, configurando um rol de direitos sobre o Estado ${ }^{12}$.

Por derradeiro, outros documentos internacionais consagram o direito ao desenvolvimento, como a Carta Africana de Direitos Humanos e dos Povos, que assegura no

10 Declaração do Rio sobre Meio Ambiente e Desenvolvimento (1992). Disponível em: <http://www.onu.org.br/rio20/img/2012/01/rio92.pdf>. Acesso em: 27 de agosto de2018.

11 Declaração e programa de ação de Viena. Conferência Mundial sobre direitos humanos. Disponível em: <https://www.oas.org/dil/port/1993\%20Declara\%C3\%A7\%C3\%A3o\%20e\%20Programa\%20de\%20Ac\%C3\%A 7\%C3\%A3o\%20adoptado\%20pela\%20Confer\%C3\%AAncia\%20Mundial\%20de\%20Viena\%20sobre\%20Direit os\%20Humanos\%20em\%20junho\%20de\%201993.pdf>. Acesso em: 28 de agosto de 2018

12 Realça-se, aqui, que não é objeto próprio deste trabalho discorrer sobre a dialética existente entre a consideração dos direitos humanos entre gerações ou dimensões, muito menos introduzi-la. Utiliza-se esta referência apenas para pontuar o locus do direito ao desenvolvimento, dentro da sua natureza de direito humano. 
art. 22 a todos os povos terem direito ao seu desenvolvimento econômico, cultural e social ${ }^{13}$, como também a Carta da Organização dos Estados Americanos e a Encíclica de Paulo VI, de 1967, acerca do Desenvolvimento dos Povos (Populorum Progresio). ${ }^{14}$

\subsection{O Desenvolvimento na ordem constitucional brasileira}

O texto constitucional nacional, já no seu preâmbulo, demonstra o compromisso em assegurar o desenvolvimento da sociedade brasileira. Ao estabelecer os objetivos fundamentais da República Federativa do Brasil, a Constituição em seu art. $3^{\circ}$, inciso II, anuncia, dentre outras premissas, a necessidade de se garantir o desenvolvimento nacional, embora o referido artigo não enuncie, nem dimensione, a amplitude do desenvolvimento almejado, os instrumentos para a sua efetivação, e tampouco o modo pelo qual se alcançará tal objetivo.

Todavia, o meio de expressão e planejamento do desenvolvimento pode ser extraído a partir do art. 21, inciso IX, que prescreve ser competência da União a elaboração e execução de planos nacionais e regionais de ordenação do território e de desenvolvimento econômico e social, assim como o inciso XX que institui as diretrizes para o desenvolvimento urbano, habitação, saneamento básico e educação, podendo englobar, ainda, conforme previsão do art. 43, da Carta Magna, a promoção do desenvolvimento das regiões econômicas e sociais, e a redução das desigualdades regionais.

Ademais, a ordem financeira e econômica positivada no texto constitucional entre os arts. 170 e 181 delimita quais são os parâmetros de atuação do Estado na Economia, assim como os fins a serem priorizados. Nesta perspectiva, o art. 170, caput, preconiza a sujeição da ordem econômica aos ditames da justiça social, ao tempo em que o inciso VII do mencionado artigo estabelece a necessidade de se reduzirem as desigualdades regionais e sociais, enquanto o art. 174, caput, dispõe que o Estado exercerá na forma da lei, as funções de fiscalização, incentivo e planejamento.

13 Carta africana dos Direitos Humanos e dos Povos. Disponível em: <http://www.achpr.org/files/instruments/achpr/achpr_instr_charter_por.pdf>. Acesso em: 27 de agosto de 2018. 14 Populorum Progresio. Carta encíclica de sobre o Desenvolvimento dos Povos. Disponível em: <http://analisesocial.ics.ul.pt/documentos/1224173714P9sED0fo7Tg77TI9.pdf>. Acesso em: 27 de agosto de 2018. 
A propósito do planejamento, o art. 165, da Constituição Federal de 1988, define os orçamentos públicos como instrumentos de fixação das diretrizes, objetivos, metas $\left(\S 1^{\circ}\right)$ e prioridades $\left(\S 2^{\circ}\right)$ da Administração Pública, além de mencionar os planos e programas, confirmando a multiplicidade de meios que as políticas públicas podem assumir em busca de sua concreção. Ademais, por meio do seu $\S 1^{\circ}$ do art. 165 , se insere na ordem jurídica nacional o plano plurianual que é o instrumento definidor, como dito, das prioridades do Estado, e não apenas do Governo, a ser executado num período de 04 (quatro) anos.

Nesta sequência, Caldas e Oliveira Junior (2016) observam que os PPA's - Planos Plurianuais federais têm dado significativa atenção à questão da infraestrutura física e o desenvolvimento regional para sua integração e redução de desigualdades, conforme também se extrai de Programas como os de Aceleração do Crescimento, de Investimentos em Logística, de Dragagem Portuária e Hidroviária, dentre outros.

Além disso, o texto constitucional, em seu art. 182, determina que a política de desenvolvimento urbano se dará mediante a devida observância das funções sociais da cidade e da garantia do bem-estar de seus habitantes; além disso, ressalta que o sistema financeiro nacional deve ser estruturado para a promoção do desenvolvimento equilibrado do país, visando atender os interesses da coletividade.

Diante do evidenciado, percebe-se expressa disposição atinente ao desenvolvimento inserido no Texto constitucional que deverá concretizar-se por via do planejamento estatal, buscando, sempre, ultrapassar a mera concepção de crescimento econômico ao inserir também o aspecto social e ambiental. Nas palavras de Ribeiro e Maciel (2017, p. 1047)

\begin{abstract}
O desenvolvimento econômico almejado pela Constituição Federal é muito mais do que um simples crescimento econômico e, nem ao menos, uma distribuição de riqueza. O que se objetiva é distribuição dessa riqueza em favor do bem-estar social e a participação da sociedade, com o fito de alcançar um crescimento com mudanças na estrutura do Estado, com diminuição da pobreza, fome, fomento à educação, saúde, entre outros fatores.
\end{abstract}

\title{
3. A INFRAESTRUTURA COMO ELEMENTO PARA O DESENVOLVIMENTO
}

Conforme comentado anteriormente, a IIRSA nasceu com um foro de diálogo dos 12 (doze) países sul-americanos e, diante de seus desdobramentos, ganhou institucionalidade a partir de sua incorporação pelo COSIPLAN da UNASUL. A Iniciativa, que no seu marco fundacional dedicou-se ao debate de inúmeros temas, terminou por dar especial atenção ao tema da integração regional de infraestrutura de transportes, energia e comunicações, visando, 
dentre outros objetivos, executar projetos de integração regional que melhorem a qualidade de vida das populações locais, consoante expressamente fixado no Comunicado de Brasília.

Ao mesmo tempo, propiciou a abertura necessária para construir um espaço de integração e união no âmbito cultural, social, econômico e político entre seus povos, dando prioridade à infraestrutura, com vistas a eliminar a desigualdade socioeconômica, alcançar a inclusão social e a participação cidadã (Tratado da UNASUL, art. $2^{\circ}$ ). De conseguinte, é notória a atenção dada à infraestrutura para alavancar a integração e o desenvolvimento regional dentro dos objetivos talhados nos documentos formadores tanto da IIRSA, quanto da UNASUL.

Sem embargo, após 18 (dezoito) anos de existência, sua audaciosa meta ainda está distante de ser concretizada, fato este reconhecido pela literatura especializada. Nessa perspectiva, Sebben (2015, p.190) conclui que "a avaliação entre o discurso anunciado e a execução dos projetos, os princípios de redução de desigualdades e aumento do valor agregado não são ou são marginalmente realizados". Ao mesmo tempo, Oliveira Junior e Vaz (2017, p. 216) asseveram que "os projetos de infraestrutura da IIRSA têm influência praticamente sobre todos os grandes biomas da região, com o potencial de criar problemas sociais e ambientais com riscos à manutenção da biodiversidade e à estrutura social das populações tradicionais".

Não obstante o já dito, a questão precípua aqui posta é analisar em que medida a infraestrutura pode ser compreendida como um elemento intrínseco atrelado ao direito humano fundamental ao desenvolvimento existente no âmbito internacional e nacional, sendo neste caso expressado pelas disposições da Constituição Federal.

Ab initio, faz-se necessário delimitar as expressões que podem apresentar o termo “infraestrutura". Enquanto, Freitas, Moura e Paula (2017) apresentam três dimensões particulares para o referido temo, a saber, a infraestrutura econômica, a infraestrutura social e a infraestrutura institucional, mencionam, ainda, que a infraestrutura é um dos pré-requisitos para a promoção do desenvolvimento.

De outro giro, o IPEA (2010), em estudo sobre infraestrutura do país, a subdivide em infraestrutura econômica e infraestrutura social e urbana. Embora a infraestrutura possa ser analisada por diferentes enfoques, é inegável o reconhecimento de sua contribuição para o processo catalizador do desenvolvimento, funcionando como alavanca para que o mesmo possa se concretizar. 
Hirschman (1961) revela que constitui um capital social básico, sem o qual os setores de produção - primário, secundário e terciário - não teriam como se desenvolver. Já para Ferreira e Neto (2010), ao investigarem a perspectiva econômica da infraestrutura, afirmam que esta tem o potencial de melhorar as condições de transportes, comunicações, fornecimento de energia e de promover efeitos multiplicadores e dinamizadores.

Conforme Padula (2010), a infraestrutura possui características fundamentais; seus serviços acarretam externalidades, viabilizando e condicionando o desenvolvimento como a interligação de inúmeras atividades econômicas e regiões. Geralmente, seus serviços são mantidos ou regulados pela Administração Pública segundo o interesse social; exigem investimentos elevados, o que gera efeitos multiplicadores e de encadeamento do setor produtivo, incrementando a demanda na economia, além de promover a criação de empregos e renda, podendo, por meio de seus investimentos, induzir mais investimentos (Padula, 2010).

Também é sabido, por estudos específicos, a relação entre o desenvolvimento econômico e social por meio de investimentos em infraestrutura. Neste sentido, Rocha e Saes (2018), ao examinarem o caso brasileiro da BR-163, concluem que os municípios localizados no entorno da rodovia possuem índice de desenvolvimento humano - IDH superiores em relação aos demais municípios comparáveis, destacando a importância de se aperfeiçoar as políticas públicas tendentes à promoção do desenvolvimento econômico a partir dos investimentos em infraestrutura.

Torna-se importante a menção supra em particular, vez que consta na carteira IIRSA o projeto brasileiro da rodovia Cuiabá-Santarém (BR-163/MT/PA), cujo objetivo se concentra em superar limites estruturais e ampliar a cobertura geográfica da infraestrutura rodoviária na região amazônica para atender uma área de 1,23 milhão de $\mathrm{Km}^{2}$, equivalente a $15 \%$ (quinze por cento) do território nacional, com 1,2 milhão de habitantes dispersos por 71 (setenta e um) municípios nos Estados do Amazonas, Pará e Mato Grosso, bem como reduzir os custos da produção local e inverter o fluxo de caminhões do Porto de Santos e Paranaguá para o Porto fluvial de Santarém/PA. ${ }^{15}$

Ainda que o estudo supramencionado ressalte os avanços econômico e social, também existem problemas de natureza socioambientais. Neste aspecto, o Plano Básico Ambiental da BR-163, segundo Verdum (2012), demonstra os riscos a que estão sujeitos os povos e comunidades tradicionais. A seu turno, Oliveira Junior e Vaz (2017) expõem a forte pressão madeireira e garimpeira para exploração de recursos em Terras Indígenas, sem que

\footnotetext{
${ }^{15}$ Disponível em: <www.irrsa.org/proyectos〉. Acesso em: 01 de setembro de 2018.
} 
haja um estudo específico sobre como as comunidades indígenas serão afetadas. Este problema, nitidamente, se enquadrada na crítica de Padula (2010) feita à IIRSA quanto ao seu distanciamento da sociedade e os impactos ambientais que têm sido alvo de constantes protestos por parte dos movimentos sociais.

De outro turno, em matéria de investimentos em infraestrutura, Suprani (2012) reconhece a importância do setor privado para o financiamento de infraestrutura em razão da vultosa quantidade de recursos financeiros necessários, além de apresentar, em certa medida, conhecimento técnico e capacidade gerencial específica.

Todavia, não se pode deixar de mencionar a centralidade dos governos na regulamentação, no planejamento e execução de projetos de infraestrutura, bem como na estrutura do financiamento, pois os grandes investimentos em infraestrutura desencadeiam adversidades, como também relevantes questões políticas.

$\mathrm{Na}$ carteira de projetos da IIRSA, se observa a predominância do investimento público correspondendo a 446 (quatrocentos e quarenta e seis) projetos de infraestrutura, o que significa dizer que 79,36\% (setenta e nove vírgula trinta e seis por cento) da carteira de projetos são financiados com recursos públicos. Embora seja impactante a presença do investimento público, constata-se que a iniciativa conta com o apoio financeiro privado, de instituições multilaterais, de bancos de fomento nacionais (v.g. o BNDES), bancos estrangeiros e recursos dos tesouros dos países, sendo que estes últimos têm o condão de atrair o desenvolvimento, a riqueza, a inclusão social e a soberania regional.

Aqui, é importante reiterar, singularmente no caso brasileiro, que as políticas públicas direcionadas à integração regional sul-americana estão compreendidas no planejamento estatal estratégico expressado pelos PPA's - Planos Plurianuais, complementados, ainda, pelas respectivas LDO's - Leis de Diretrizes Orçamentárias e LOA's - Leis Orçamentárias Anuais. E, repita-se, ainda em Programas como os de Aceleração do Crescimento, de Investimentos em Logística, de Dragagem Portuária e Hidroviária, dentre outros. Política pública, segundo Caldas e Oliveira Junior (2016, p. 138), vale esclarecer

Revela-se num processo, ou conjunto de processos regulados sob uma perspectiva jurídica, implicando prestações estatais com objetivos estrategicamente planejados para atender interesses da sociedade, por intermédio de planos, programas e projetos em que sejam estipuladas como ações ou metas a serem cumpridas, inclusive com participação popular, e instrumentalizadas por um conjunto normativo no qual plasmada a vontade política a concretizar-se em um determinado período de tempo. 


\title{
A INFRAESTRUTURA COMO ELEMENTO DO DIREITO HUMANO AO DESENVOLVIMENTO NO \\ MARCO DA INTEGRAÇÃO REGIONAL SUL-AMERICANA
}

A acepção supradescrita torna-se indispensável quando se verifica que para realizar o desenvolvimento, a redução de assimetrias, o pleno respeito à inclusão social e a participação cidadã por via da integração regional de infraestrutura, depende-se, em grande medida, de ações estatais estratégicas, traduzidas em políticas públicas concretizadas em um processo de criação de metas, finalidades públicas com a indispensável participação popular, instrumentalizadas por um arcabouço normativo contando com forte apoio financeiro governamental para fomentar exatamente o desenvolvimento, a riqueza e a inclusão social.

É inconteste na literatura a importância da infraestrutura para o desenvolvimento, ao permitir a integração física do território dos Estados. Essa perspectiva se traduz na intervenção do Ex-Presidente do BNDES, em sua intervenção no Seminário BNDES-CAF, em 2003, ocasião em que destacou

\begin{abstract}
A infraestrutura gera as externalidades que definem, em última instância, o nível de produtividade macroeconômica média de todo o processo produtivo. Gera encomendas encadeadas que viabilizam o desenvolvimento de atividades industriais de suporte, multiplica empregos. A infraestrutura é a locomotiva do desenvolvimento. Precisamos colocar a locomotiva sul-americana funcionando a todo vapor ${ }^{16}$
\end{abstract}

Resta evidente, de conseguinte, que, quanto à hodierna acepção de desenvolvimento sustentável, o papel da infraestrutura é fundamental ao permitir uma melhor integração física entre os Estados em vista de uma união econômica e política, segundo um processo de globalização, apresentando-se, assim, como um componente imprescindível do direito ao desenvolvimento, a sua vez havido como um direito fundamental de solidariedade.

\section{CONSIDERAÇÕES FINAIS}

Exatamente diante da necessidade de criação de infraestrutura para uma melhor integração dos Estados ao buscarem o seu desenvolvimento, surge a IIRSA com o escopo de construir uma rede de transportes, energia e comunicações voltada para o desenvolvimento regional, a melhoria da qualidade de vida das populações locais, construindo um espaço de integração e união no âmbito cultural, social, econômico e político entre seus povos, com vistas a eliminar a desigualdade socioeconômica, alcançar a inclusão social e a participação cidadã.

16 BNDES. Banco Nacional de Desenvolvimento Econômico y Social. Disponível em http://www.bndes.gov.br/SiteBNDES/export/sites/default/bndes_pt/Galerias/Arquivos/conhecimento/seminario/c af_abertura1.pdf. Acesso 01 de dezembro de 2014. 
Ademais, percebe-se que o planejamento, execução e desenvolvimento da Carteira IIRSA depende de ações dos Estados envolvidos; em particular, no caso brasileiro, observa-se que a integração regional sul-americana está compreendida no planejamento estatal estratégico por meio de políticas públicas nacionais, instrumentalizadas por um arcabouço normativo como os PPA's, com seus planos e programas estatais, os quais estipulam metas a serem cumpridas em certo espaço de tempo, inclusive com participação popular, consubstanciando-se em finalidades públicas devidamente positivadas.

De outra face, o direito ao desenvolvimento compreendido como um direito humano fundamental de solidariedade, encontra-se plasmado na ordem jurídica internacional e expressado, especialmente, na Declaração sobre o Direito ao Desenvolvimento, de 1986.

Não obstante o conceito estabelecido em tal declaração seja bastante amplo, o próprio texto declarativo expõe no seu preâmbulo que o desenvolvimento é um processo econômico, social, cultural e político abrangente, que visa ao constante incremento do bemestar de toda a população e de todos os indivíduos com base em sua participação ativa, livre e significativa no desenvolvimento e na distribuição justa dos benefícios daí resultantes.

Assim, considerando como primeira premissa o objetivo da IIRSA de construir uma rede de infraestrutura focada na integração regional, que produza tanto desenvolvimento e a integração regional, envolvendo a participação das sociedades envolvidas, vale lembrar que a expressão de tais metas também está plasmada no Tratado constitutivo da UNASUL, cuja instituição absorve a IIRSA na qualidade foro técnico do COSIPLAN.

Enquanto segunda premissa, qual seja, a necessidade de os Estados-membros adotarem ações para a construção desta rede de infraestrutura, no caso brasileiro, tal esforço traduz-se em políticas públicas, instrumentalizadas pela participação popular, dentro de um arcabouço normativo que, inclusive, versa a declaração sobre o direito ao desenvolvimento, que define este último e lhe confere o caráter de direito humano inalienável.

De conseguinte, diante de tais premissas e, orientado pela dicção de que a infraestrutura regional deve ser construída a fim de se perseguir o desenvolvimento, extrapolando a seara econômica, mas repartindo seus frutos com o objetivo da acarretar a diminuição de desigualdade, a melhoria das condições de vida e a participação popular, é que se faz necessário verificar a infraestrutura no âmbito da IIRSA como elemento não apenas para o desenvolvimento, mas também como integrante ao direito ao desenvolvimento, o que permite a favor das populações envolvidas uma forma de exercer e exigir a entrega dos 
projetos de infraestrutura de forma que absorvam seus reais benefícios e não se tornem promessas de um futuro incerto.

\section{REFERÊNCIAS}

BEDIN, Gilmar Antônio. Direitos Humanos e Desenvolvimento: algumas reflexões sobre a constituição do direito ao desenvolvimento. In: Desenvolvimento em Questão. Editora Unijuí. Ano 1. N.1 jan/jul, 2003. P. 123-149. Disponível em: $<$ https://www.revistas.unijui.edu.br/index.php/desenvolvimentoemquestao/article/view/70>. Acesso em 22 de agosto de 2018.

CALDAS, Roberto Correia da Silva Gomes; DIZ, Jamile Bergamaschine Mata . Soberania permanente sobre as riquezas e os recursos naturais dos Estados: uma interpretação sistêmica do artigo 47 do Pacto Internacional de Direitos Civis e Políticos. Juris Plenum Direito Administrativo, v. III, p. 157-174, 2016.

CALDAS, Roberto Correia da Silva Gomes; OLIVEIRA JUNIOR, Joaner Campello. A integração da infraestrutura regional e a implementação de políticas públicas: análise do caso brasileiro. In: Revista de Direito Brasileira - RDB. v. 15. n. 6. 2016. p.133-147. Disponível em:

http://www.indexlaw.org/index.php/rdb/issue/view/v.15\%20n.6\%20\%282016\%29/showToc. Acesso em 21 de agosto de 2018.

CARVALHO, Glauber Cardoso; ROSEVICS, Larissa. A política externa do governo Lula para a América do Sul: Unasul e Unila. In: Por uma integração ampliada da América do Sul no século XXI. Sarti, Ingrid et all (orgs.). Rio de Janeiro: Perse, 2013

DABÈNE, Oliver. A quarta onda de regionalismo: Os Desafios do Desenvolvimento da América Latina. In: QUENAN, Carlos; VELUT, Sébastien (orgs.). Os desafios do desenvolvimento da America Latina: Dinâmicas socioeconômicas e políticas públicas França: Agence Française de Développment, 2014.

FERREIRA, Iansã Melo; NETO, Carlos Campos. Impacto da infraestrutura econômica sobre o desenvolvimento. In: Repositório de Conhecimento do IPEA. 2010. Ano 7. Edição 61. p.12 . Disponível em: http://repositorio.ipea.gov.br/bitstream/11058/8507/1/Impacto\%20da\%20infraestrutura\%20ec on $\%$ C3\%B4mica\%20sobre\%20o\%20desenvolvimento.pdf. Acesso em 27 de agosto de 2018.

FREITAS, César Augustus Labre Lemos de; MOURA, João Gonsalo de; PAULA, Ricardo Zimbrão Affonso de. Infraestrutura e desenvolvimento: impactos econômicos decorrentes do afastamento de rodovias maranhenses inseridas no eixo da tora das emoções; In: Revista de economia da UEG. vol. 13. n.1. jan/jun, 2017. p. 118-135. Disponível em: <www.revista.ueg.br/index.php/economia/article/download/5977/4615>. Acesso em $28 \mathrm{de}$ agosto de 2018.

GONÇALVES, José Botafogo; OLIVEIRA, José. Integração, desenvolvimento e infraestrutura na América do Sul. In: Cadernos Adenauer XII. 2011. n.1. p. 8-20. Disponível 
em: http://www.kas.de/wf/doc/kas_23067-1522-5-30.pdf?110825220155. Acesso em 23 de agosto de 2018.

HIRSCHMAN, Albert O. Estratégia do desenvolvimento econômico. Rio de Janeiro: Fundo de Cultura, 1961.

IIRSA. Comunicado de Brasília (2000a). http://www.iirsa.org/admin_iirsa_web/Uploads/Documents/comunicado_brasilia_esp.pdf.

Acesso de 1 de agosto de 2014.

. Plano de Ação para a integração de infraestrutura regional na América do Sul (2000b).

Disponível

em:

http://www.iirsa.org/admin_iirsa_web/Uploads/Documents/Plan\%20de\%20Acción\%20Monte video\%20final.pdf. Acesso em 1 de agosto de 2014.

IPEA. Infraestrutura social e urbana no Brasil. Subsídios para uma agenda de pesquisa e formulação de políticas públicas. Livro 6. V. 2. Instituto de Pesquisa Econômica Aplicada. Brasília: $\quad$ Ipea, $2010 . \quad$ Disponível em http://www.ipea.gov.br/portal/images/stories/PDFs/livros/livros/42543_Livro_InfraestruturaS ocial_vol2.pdf Acesso em 01 de setembro de 2018.

IPEA. Infraestrutura econômica no Brasil: diagnósticos e perspectivas para 2025. Instituto de Pesquisa Econômica Aplicada. - Brasília: Ipea, 2010. Disponível em http://www.ipea.gov.br/portal/images/stories/PDFs/livros/livros/Livro_InfraestruturaSocial_v ol1.pdf. Acesso em 01 de setembro de 2018

KINOSHITA, Fernando; FERNANDES, Joel A. O direito ao desenvolvimento como um Direito Humano e prerrogativa dos Estados nas relações internacionais do século XXI. Âmbito Jurídico. Rio Grande, XI, n. 50, fev 2008. Disponível em: <http://www.ambito-juridico.com.br/site/?n_link=revista_artigos_leitura\&artigo_id=5912>.

Acesso em: 30 nov 2017.

LÓPEZ, Rodolfo. Nuevo instrumento de regionalismo sudamericano. Resultados de la Iniciativa para la Integración de la Infraestructura Regional Sudamericana. 2012. P. 217-237. In: BERNAL-MEZA, Raúl; QUINTANAR, Silvia Victoria. Regionalismo e Ordem Mundial: Suramérica, Europa, China. Buenos Aires: Grupo Editor Latinoamericano, 2012.

MARTINELLI, Adriano Justi. O direito humano e fundamental ao desenvolvimento e o seu regime jurídico. In: Constituição, economia e desenvolvimento. Revista da Academia Brasileira de Direito Constitucional. Curitiba, 2012. v.4. n.7. jul./dez. p.401-438. Disponível em: <http://www.abdconst.com.br/revista8/direitoAdriano.pdf >. Acesso em 20 de agosto de 2018.

MATA DIZ, Jamile Bergamaschine; SOUZA, Laura Felipe de. O desenvolvimento regional e a proteção ambiental: uma análise da iniciativa para a integração da infraestrutura regional Sul-Americana. Revista de Direito Ambiental: RDA, v. 20, n. 77. São Paulo: Ed. RT, jan./mar.2015.

MOISÉS, Cláudia Perrone. Direito ao desenvolvimento e investimento estrangeiros. São 
Paulo: Editora Oliveira Mendes, 1998.

NERY, Tiago. UNASUL: a dimensão política do novo regionalismo sul-americano. Cad. CRH, Salvador, v. 29, n. spe3, p. 59-75 2016. Disponível em http://www.scielo.br/scielo.php?script=sci_arttext\&pid=S0103-

49792016000600059\&lng=en\&nrm=iso. Acesso em 15 de janeiro de 2017. http://dx.doi.org/10.1590/S0103-49792016000400005.

NUNES, Raul Cavedon; RODRÍGUEZ, Vitória Gonzales. A política externa brasileira de Temer-Serra: retração política e subordinação econômica. In: Boletim de Conjuntura NERINT. v.1. n.4.p.1-91. Porto Alegre, 2017. Disponível em: https://www.ufrgs.br/nerint/wp-content/uploads/2017/03/POR-Nunes-Rodriguez.pdf. Acesso em 18 de agosto de 2018.

OLIVEIRA JUNIOR, Joaner Campello de; VAZ, Natália Carolina de Oliveira. Os projetos de infraestrutura da IIRSA e a violação dos direitos indígenas. In: Aracê Direitos Humanos em Revista. v. $4 . \quad$ n.5. 2017. p. 202-218. Disponível em $<$ https://arace.emnuvens.com.br/arace/article/view/142>. Acesso em 30 de agosto de 2018

PADULA, Raphael. Integração Regional de Infraestrutura e comércio na América do Sul nos anos 2000: uma análise político-estratégica. Rio de Janeiro: Universidade Federal do Rio de Janeiro - UFRJ, 2010. 311 páginas. Doutorado em engenharia de produção. Programa de Pósgraduação em engenharia de produção - COPPE/UFRJ. Disponível em <http://objdig.ufrj.br/60/teses/coppe_d/RaphaelPadula.pdf>. Acesso em 29 de agosto de 2018.

, Raphael. Notas sobre a integração de infraestrutura na América do Sul: da IIRSA ao Cosiplan da Unasul. In: Por uma integração ampliada da América do Sul no século XXI. Sarti, Ingrid et all (orgs.). Rio de Janeiro: Perse, 2013.

PEIXINHO, Manoel Messias; FERRARO, Suzani Andrade. Direito ao Desenvolvimento como Direito Fundamental, 2013. p.6952-6973. Disponível em: <http://www.publicadireito.com.br/conpedi/manaus/arquivos/anais/bh/manoel_messias_peixi nho.pdf $>$. Acesso em 28 de agosto de 2018.

RIBEIRO, Maria de Fátima; MACIEL, Lucas Pires. A tributação como vetor para o atingimento do direito ao desenvolvimento econômico e sustentável. In: Anais do V Congresso Nacional da FEPODI - Recurso eletrônico on-line. CAMPELLO, Lívia Gaigher Bosio; LANNES, Yuri Nathan da Costa. Florianópolis, 2017. p. 1046-1058. Disponível em https://www.conpedi.org.br/publicacoes/696vp84u/bloco-unico/5E5V5Xx9vLShoAnX.pdf Acesso em 29 de agosto de 2018.

ROCHA, Fernando Vinícius da; SAES, Maria Sylvia Macchione. Desenvolvimento econômico e social por meio de investimentos em infraestrutura: o caso da BR-163. In: Desenvolvimento em Questão. Editora Unijuí. Ano 16. n.42. jan/mar, 2018. p. 99-123. Disponível

em: <https://www.revistas.unijui.edu.br/index.php/desenvolvimentoemquestao/article/view/6248> . Acesso em 25 de agosto de 2018. 
SEBBEN, Fernando Dall'Onder. Infraestrutura e desenvolvimento: Estudo de Caso sobre IIRSA e COSIPLAN. Porto Alegre: Universidade Federal do Rio Grande do Sul, 2015. 280 páginas. Doutorado em Estudos Estratégicos Regionais. Programa de pós-graduação em economia da Faculdade de Ciências Econômicas da UFRGS. Disponível em: <https://www.lume.ufrgs.br/handle/10183/131654>. Acesso em 20 de agosto de 2018.

SENGUPTA, Arjun K. Conceptualizing the right to development for the twenty-first century. In: Realizing the Right to Development. Essays in Commemoration of 25 Years of the United Nations Declaration on the Right to Development. New York and Geneva, 2013. p. 67-87. Disponível em: <https://www.ohchr.org/Documents/Publications/RightDevelopmentInteractive_EN.pdf> Acesso em 29 de agosto de 2018.

SUPRANI, Rodrigo Otávio de Faria. O investimento em infraestrutura: desenvolvimento, comércio exterior e o caso brasileiro. Rio de Janeiro: Universidade Federal do Rio de Janeiro, 2012. 81 páginas. Mestrado em Economia Política Internacional. Programa de pós-graduação em Economia Política Internacional da Universidade Federal do Rio de Janeiro, Rio de Janeiro. Disponível em: <http://www.ie.ufrj.br/images/posgraducao/pepi/dissertacoes/PEPI_DISSERTAO_RODRIGO_FARIA_SUPRANI.pdf $>$. Acesso em 28 de agosto de 2018.

VERDUM, Ricardo. As obras de infraestrutura do PAC e os povos indígenas na Amazônia Brasileira. Nota Técnica 09. Observatório de Investimentos na Amazônia. INESC, Setembro/2012. 